\title{
1 Effects of the anesthetic MS-222 on silver pomfret (Pampus argenteus) juveniles under aquaculture treatment stresses
}

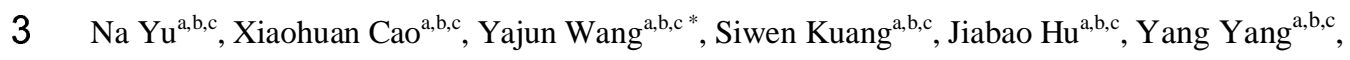

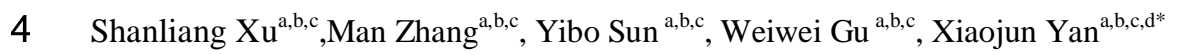

5 a Key Laboratory of Applied Marine Biotechnology, Ningbo University, Ministry of Education,

6 Ningbo,China

$7 \quad{ }^{\mathrm{b}}$ Marine Biotechnology Laboratory, Ningbo University, Ningbo, China

$8 \quad{ }^{\mathrm{c}}$ College of Science \& Technology Ningbo University, Ningbo, China

$9{ }^{\mathrm{d}}$ Li Dak Sum Yip Yio Chin Kenneth Li Marine Biopharmaceutical Development Research platform,

10 Ningbo,China

11 Correspondence:

12 *Dr Yajun Wang

13 Postal address: School of Marine Sciences, Ningbo University, Ningbo, China, 315211.

14 Tel: +86-574-87600170; Fax: +86-574-87609581.

15 E-mail address: wangyajun@nbu.edu.cn

16 *Dr Xiaojun Yan

17 Postal address: Key Laboratory of Applied Marine Biotechnology, Ningbo University, Ministry of

18 Education, Ningbo 315211.

19 Tel: +86-574-87609570; Fax: +86-574-87609570.

20 E-mail address: yanxiaojun@nbu.edu.cn

\section{Abstract} However, P. argenteus is sensitive to many stress factors and susceptible to injury. This problem could 25 be resolved using anesthesia. We determined the lowest effective dose (LED) of tricaine 26 methanesulfonate (MS-222) and assessed the longest safe deep anesthesia time and effect after 27 aquaculture treatment stresses. P. argenteus juveniles were exposed to six concentrations of MS-222 $28\left(10,25,50,75,100\right.$, and $\left.125 \mathrm{mg} \mathrm{L}^{-1}\right)$; LED was established at $75 \mathrm{mg} \mathrm{L}^{-1}$. The juveniles were exposed 29 to different deep anesthesia times $(4,7,10,12$, and $15 \mathrm{~min})$ at $75 \mathrm{mg} \mathrm{L}^{-1}$; the longest safe deep 
control group (CG), draining group (DG, drain), anesthetic group (AG, drain + MS-222 + aquaculture treatment); and non-anesthetic group (NAG, drain + aquaculture treatment). Plasma cortisol levels in the NAG, AG, DG, and CG groups were $38.739 \pm 1.065$ (highest), $25.083 \pm 0.587,28.644 \pm 0.612$, and

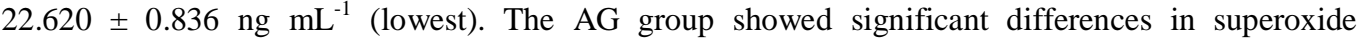
dismutase, catalase, and malondialdehyde activities, except for glutathione. HSP70, HSP90, GR1, and GR2 mRNA levels in the NAG group increased sharply in response to stressors. GR1 and GR2 mRNA levels in the AG group also increased significantly, whereas HSP70 and HSP90 mRNA levels showed no significant differences. Thus, MS-222 can reduce oxidative damage, stress reaction, and resistance to aquaculture treatment stresses in $P$. argenteus.

\section{Key words: MS-222, plasma cortisol, antioxidant capability, stress-related gene expression, silver} pomfret, aquaculture treatment stresses

\section{Introduction}

Anesthetic agents are widely used in modern aquaculture and have practical relevance in diverse husbandry manipulations such as grading, measurement, blood sampling, tagging, transportation, vaccination, and surgery (Wagner et al., 2015). These routine operations often affect the physiological condition and well-being of organisms and may result in undesirable reactions such as oxidative and immune stresses (Zhang et al., 2015). Under such circumstances, the use of anesthetic agents may be beneficial or even necessary. A number of chemical anesthetics have been used in fishery research, for example, MS-222, clove oil, benzocaine, and 2-phenoxyethanol (Heo and Shin, 2010) (Popovic et al., 2012; Barata et al., 2016). The most commonly used anesthetic in aquaculture practice and research is MS-222 (Popovic et al., 2012). MS-222 is a white crystalline powder that is easily dissolved in water, and rapid induction and full recovery are observed in animals. Currently, only MS-222 is licensed for use in food fish in the USA and European Union.

Cortisol is the primary glucocorticoid in teleost fish, and it is produced by the adrenal cortex or the adrenal analogue in teleost fish (the internal cells of the head kidney) (Bern, 1967). It plays an essential role in a plethora of intermediary metabolism, reproduction, and anti-inflammatory functions and stress responses (Charmandari et al., 2005). Cortisol also functions as a mineralocorticoid in teleosts, as they lack the capacity to synthesize aldosterone; thus, it is important for the maintenance of hydromineral 
59 balance (Wendelaar Bonga, 1997). The production of corticosteroids is under the control of the

60 hypothalamus-pituitary-interrenal axis (Mommsen et al., 1999). Most glucocorticoid effects occur at

61 the transcriptional level and are mediated by the glucocorticoid receptor (GR) (Bamberger et al., 1996;

62 Schoneveld et al., 2004). In teleosts, two types of GRs are present: GR1 and GR2. GR1 was first

63 identified in the rainbow trout (Ducouret et al., 1995), and cDNAs of piscine GR1 have been

64 characterized in tilapia (Tagawa et al., 1997) and the common carp (Stolte et al., 2008). GR2 cDNAs

65 have been characterized in the rainbow trout, common carp (Bury et al., 2003), and zebrafish (Alsop

66 and Vijayan, 2008).

67 Heat shock proteins (HSPs) belong to one of the most conserved and important protein families, and

68 they have been studied extensively as molecular chaperones with important roles in protein folding and

69 translocation (Ming et al., 2010). HSP70, as the most conservative protein in the HSP family, plays an

70 important role in regulating the restructure of new synthetic proteins and denatured proteins (Jiang et

71 al., 2012). In fish, an increase in HSP70 expression not only reflects the body's response to oxidative

72 stress but also alleviates the adverse effects of oxidative stress with its antioxidant function ( $\mathrm{Li}$ et al.,

73 2014; Pierron et al., 2009). HSP90 may be involved in the cell cycle and signal transduction process

74 and maintenance of a stable cell, and it plays an important role in the response to the stimulation of fish

75 (Wang et al., 2004). Changes in the expression of HSP90, like HSP70, often serve as a reference index

76 for stress in fish.

77 The silver pomfret (Pampus argenteus), a commercially important fish, has a wide distribution from 78 the Arabian Gulf, Indian Ocean, and East Indies to Japan (Sun et al., 2017). Since the 1990s, 79 wild-caught $P$. argenteus fisheries have suffered a severe decline because of over-fishing (Liu and 80 Zhan, 1999) in the East China Sea. To enhance production, artificial breeding techniques have been 81 studied in China and Kuwait (Huang et al., 2010), and studies on different aspects such as feeding 82 behavior, breeding, growth-related genes, and health management (Shi et al., 2009a; Shi et al., 2009b;

83 Sulaimanm and Charlesm, 2007; Azad et al., 2007) have been performed to develop culture techniques

84 for P. argenteus. However, P. argenteus is sensitive to many types of stress factors, such as procedures

85 for handling, grading, and transportation. Previous aquaculture studies on P. argenteus exposed to a transportation stressor (Zhang et al., 2017) showed that the fish panicked, leading to injury or even 
87 death. Furthermore, the fish kept swimming under normal conditions and exhibited relatively low

88 tolerance to starvation (Liao et al., 2017). Therefore, low growth rates and high mortality have been

89 found to be associated with the culture practices for P. argenteus. Reduction of stress in fish during

90 commercial production practices is a major factor in the aquaculture industry. Currently, high

91 concentrations of MS-222 are used for the sampling of P. argenteus; however, there is limited

92

93

94

95

96

97

98

99

100

101

102

103

104

105

106

107

108

109

110

111

112

113

114

information on an appropriate concentration of MS-222 for reducing stress in this species.

Because of growing interest in the culture of $P$. argenteus and lack of detailed practical information on the administration of anesthetics, the first aim of this study was to determine the lowest effective dose (LED) on the basis of induction and recovery times of MS-222 that could be efficiently used for $P$. argenteus. The second aim was to determine the longest safe deep anesthesia time of MS-222 under LED. The effects of physiological and biochemical indicators during aquaculture treatment were also studied. Plasma cortisol levels and antioxidant capability were assessed as physiological and biochemical indicators, and the expression of stress-related genes as molecular biomarkers was analyzed to reflect the effect of each treatment.

\section{Material and Methods}

\section{Fish and experimental conditions}

Specimens of $P$. argenteus were collected from Xiangshan Island, Xiangshan, Ningbo in Zhejiang Province, China. No specific permission was required for the collection of $P$. argenteus from the sample sites, which were not protected areas of land. In addition, $P$. argenteus is not an endangered or protected species. Four-month-old fingerlings ( $250 \mathrm{fish}$; average weight, $11.2 \pm 1.5 \mathrm{~g}$; length, $7.5 \pm 1.6$ $\mathrm{cm}$ ) were acclimated in six circular plastic tanks with a black background (capacity, $1200 \mathrm{~L}$ ) and a constant flow of aerated seawater for two weeks before the experiment. For acclimation, the fish were fed twice a day (07:00 and 17:00) with a commercial diet (Shimonoseki, Japan) equivalent to 1.5\% of their body weight, and feed was deprived $24 \mathrm{~h}$ before the experiment. The daily seawater exchange rate was $60 \%$. The tanks were cleaned daily, and seawater quality parameters during the acclimatization period and throughout the experiments were as follows: seawater temperature, $29 \pm 0.5{ }^{\circ} \mathrm{C} ; \mathrm{pH}, 7.9 \pm$ 0.2 ; salinity, $30 \pm 0.3 \mathrm{ppt}$; dissolved oxygen, $6.1 \pm 0.6 \mathrm{mg} \mathrm{L}^{-1}$; and natural photoperiod.

\section{Anesthetic agent}



minutes before the start of each experiment; MS-222 was dissolved in seawater and added to anesthetic test tanks.

\section{LED of MS-222}

119 Changes in the physiological status of the anesthetized fish were assessed in three consecutive stages

120 for induction (I) and three stages for recovery (R), as described by Summerfelt and Smith with slight

121 modifications based on the species-specific behavioral response of P. argenteus (Table 1). After two

122 weeks of acclimation, the fish were gently scoop-netted and placed in 18 anesthetic test tanks (capacity,

$12320 \mathrm{~L}$ ) containing different doses of the anesthetic solutions. The following doses of MS-222 were used:

$12415,25,50,75,100$, and $125 \mathrm{mg} \mathrm{L}^{-1}$. Only one anesthetic dose was tested at a time. The induction and

125 recovery times for all anesthetics were measured under the same experimental conditions by using a

126 digital stopwatch. The seawater in each tank was aerated to facilitate complete mixing. Nine fish were

127 used for each concentration of MS-222 (3 fish per tank; total, 54 fish). An effective dose of an

128 anesthetic is the dose that produces general anesthesia (I3) within $3 \mathrm{~min}$ and allows recovery (R3)

129 within 5 min (Mohammadi and Khara, 2015). When the P. argenteus specimens reached I3, they were

130 immediately netted from the test tanks and placed on a wet surface for a period of $90 \mathrm{~s}$. The duration of

131 this period was sufficient to measure the length and weight of the fish. Subsequently, the fish were

132 transferred to a recovery tank (capacity, $500 \mathrm{~L}$ ) filled with fresh, aerated seawater for recording the

133 stages of anesthesia recovery. Accordingly, LED of MS-222 was determined. After the anesthetic

134 treatment, the fish exposed to the same dose of anesthetic were maintained in the same recovery tank to

135 assess recovery time and recovery rate and observe behavioral changes during and after the treatment

136 period of 7 days. The commercial feed was supplied the next morning, and the tested fish were not 137 used again for the subsequent tests. 
Table 1 Stages of anaesthetic induction and recovery in Pampus argenteus

$\begin{array}{ll}\text { Stage } & \text { Behavioural response of Pampus argenteus } \\ \text { I1 } & \text { Loss of balance, slow swimming, partial inhibition of reactions to external } \\ \text { I2 } & \text { Erratic swimming. Fish still react to strong stimuli } \\ \text { I3 } & \text { Fish lay on the tank bottom. Slow decrease in opercular rate. No reaction to } \\ \text { stimuli } & \text { Fish stop movement (over dose and or longer immersion in anaesthetic solution). } \\ \text { I4 } & \text { Subsequent death } \\ \text { R2 } & \text { Fish still lay on bottom of the tank. Start of movement. } \\ \text { R1 } & \text { Normal swimming. Reaction to slight stimuli. } \\ & \end{array}$

\section{Longest safe deep anesthesia time under LED}

145 After two weeks of acclimation, 45 fingerlings were randomly divided into five groups (3 tanks per

146 group; 3 fish per tank) and placed in anesthetic test tanks (capacity, $20 \mathrm{~L}$ ) containing $75 \mathrm{mg} \mathrm{L}^{-1}$ of

147 MS-222. Only one time of deep anesthesia was tested at a time. The induction and recovery times for

148 all the groups were measured under the same experimental conditions by using a digital stopwatch. The

149 recovery time and recovery rate of the fish were recorded. When the fish reached I3, the time of deep

150 anesthesia $(5,7,10,12$, and $15 \mathrm{~min})$ was recorded, and the fish were transferred to a recovery tank

151 (capacity, 500 L) filled with fresh, aerated seawater for recording the stages of anesthesia recovery.

152 After the anesthesia treatment, the fish exposed to the same time of deep anesthesia were maintained in

153 the same recovery tank to assess the recovery time and recovery rate and observe behavioral changes

154 during and after the treatment period of 7 days. The commercial feed was supplied the next morning,

155 and the tested fish were not used again for the subsequent tests. 
156

157

158

159

160

161

162

163

164

165

166

167

168

169

170

171

172

173

174

175

176

177

178

179

180

181

182

183

\section{Aquaculture treatment stresses}

After two weeks of acclimation, healthy fish were randomly divided into four groups $(\mathrm{n}=30)$ and placed in anesthetic test tanks (capacity, $500 \mathrm{~L}$ ) to evaluate how different handling procedures during aquaculture treatment would affect stress responses and whether MS-222 has a stress-relieving effect on $P$. argenteus. The four treatment groups were as follows: control group (CG), draining group (DG; seawater drained off, $0.03 \mathrm{~m}^{3} \mathrm{~min}^{-1}$ for $10 \mathrm{~min}$ ), anesthetic group (AG; seawater drained off like in the DG group; a high dose of MS-222 was added until the dose in the seawater was $75 \mathrm{mg} \mathrm{L}^{-1}$, the fish were chased with a PVE pipe [25 circles per min for $5 \mathrm{~min}$ ], and seawater was added [0.06 $\mathrm{m}^{3} \mathrm{~min}^{-1}, 5$ min]), and non-anesthetic group (NAG, similar to the AG group, without anesthesia). Nine samples (3 tanks per group; 3 fish per tank) were obtained from each group. Blood was collected using heparinized syringes and then centrifuged at $1,500 \times g$ for $15 \mathrm{~min}$ at $4{ }^{\circ} \mathrm{C}$. The supernatant was transferred to a 1.5-mL centrifuge tube and stored at $-80^{\circ} \mathrm{C}$ until analysis. The kidney and liver were quickly removed (placed on ice) and then stored at $-80^{\circ} \mathrm{C}$ until subsequent analyses.

\section{Blood and liver parameters}

\section{Plasma cortisol level}

Fish cortisol levels were determined using the Fish Cortisol Enzyme-linked Immunosorbent Assay Kit ${ }^{\circledR}$ (Xin Yu Biotech, Shanghai), according to the manufacturer's instructions. This kit uses the quantitative sandwich enzyme immunoassay technique. The microplate provided in this kit is pre-coated with a monoclonal antibody specific for cortisol.

\section{Liver superoxide dismutase, catalase, and glutathione activities and malondialdehyde content}

The liver samples were homogenized in physiological saline (1:9 dilution) and then centrifuged at $600 \times g$ and $4 \square$ for $10 \mathrm{~min}$. Superoxide dismutase (SOD), catalase (CAT), and glutathione (GSH) activities and malondialdehyde (MDA) content of the supernatant were measured using the total SOD assay kit (hydroxylamine method), CAT assay kit (visible light), reduced GSH assay kit (spectrophotometric method), and MDA assay kit (thiobarbituric acid method). These kits were purchased from Nanjing Jiancheng Biological Engineering Research Institute, China. The hepatic protein content was measured using the Micro BCA Protein Assay Kit (Beijing ComWin Biotech Co., Ltd., China). 


\section{Real-time quantitative polymerase chain reaction}

185 Total RNA was extracted from the kidney tissue by using TRIzol® Reagent (Invitrogen, USA),

186 according to the manufacturer's instructions. The RNA quality was assessed using $1 \%$ formaldehyde

187 denaturing agarose gel electrophoresis. The purified RNA generally had an OD260/OD280 of 1.8-2.

188 The cDNA was synthesized using the RT-PCR Kit (TaKaRa, Japan), according to the instructions of

189 SYBR $®$ PrimeScript ${ }^{\mathrm{TM}}$. To adjust the quantity of input cDNA, the housekeeping gene $\beta$-actin was used

190 as the internal control. The target and reference genes used in this study were based on published

191 information (Table 2). The stress-related genes selected were as follows: heat shock proteins (HSP90

192 and HSP70) and glucocorticoid receptors (GR1 and GR2). All primers were synthesized by Shanghai

193 Biocolor BioScience \& Technology Company (China). Real-time quantitative polymerase chain

194 reaction (RT-qPCR) was performed using the Mastercycler EP Gradient Realplex (Eppendorf,

195 Germany). SYBR Green (Roche, USA) was used as the fluorescent dye, and the manufacturer's

196 protocol was used. RT-PCR was performed using a total volume of $20 \mu \mathrm{L}$. The cycling conditions were

197 as follows: denaturation at $95{ }^{\circ} \mathrm{C}$ for $2 \mathrm{~min}$, followed by 40 cycles of denaturation at $95{ }^{\circ} \mathrm{C}$ for $15 \mathrm{~s}$,

198 annealing at $60{ }^{\circ} \mathrm{C}$ for $15 \mathrm{~s}$, and extension at $72{ }^{\circ} \mathrm{C}$ for $20 \mathrm{~s}$. Each qPCR was performed in triplicate,

199 and the data for each sample were expressed relative to the expression levels of $\beta$-actin by using the $200 \quad 2^{-\triangle \Lambda C T}$ method.

201

Table 2 The primers used in this study for real-time qPCR

\begin{tabular}{ccc}
\hline Gene & Forward $\left(5^{\prime}-3^{\prime}\right)$ & Reverse $\left(5^{\prime}-3^{\prime}\right)$ \\
\hline HSP70 & GATGCAGCCAAGA & GCTTCCCTCCATCT \\
& ACCAGGTGG & CCGATCACC \\
HSP90 & GACCAAGCCTATCT & TTGACAGCCAGGT \\
& GGACCCGCAAC & GGTCCTCCCAGT \\
GR1 & ATCGTCGCTCCTCT & GACAACGCTGGTTT \\
& GTATC & ATGC \\
GR2 & ACGGACAGGGCAG & GAGCCAGGCAGTG \\
& GATTT & TTTGA \\
$\beta$-actin & ACCCAGATCATGTT & ATGAGGTAGTCTGT \\
& CGAGACC & GAGGTCG \\
\hline
\end{tabular}

\section{Statistical analysis}

203 The results were presented as arithmetic mean \pm standard deviation of the mean (SD) values. The

204 data were statistically analyzed using SPSS 16.0 for Windows (SPSS Inc, Chicago, IL, USA). The 
205 relevant variables for each experimental group were compared using one-way analysis of variance,

206 followed by the Tukey tests to detect significant differences. The minimum significance level was set

207 at $\mathrm{P}<0.05$ in all cases.

208 3. Results

209 Anesthetic efficacy

210 LED

211 Significant differences $(\mathrm{P}<0.05)$ in the induction and recovery stages at different doses of MS-222

212 were detected for P. argenteus (Table 3). The induction times decreased significantly with increasing

213 doses of MS-222. However, the recovery times increased with increasing doses of MS-222 (P $<0.05)$.

214 At 10 and $25 \mathrm{mg} \mathrm{L}^{-1}$ of MS-222, the fish did not complete anesthetic induction and stayed at a light

215 sedation stage (I1, Table 1). Considering the accepted efficacy criteria of general anesthetic induction

216 time (I3) within $3 \mathrm{~min}$ and recovery time (R3) within $5 \mathrm{~min}$, the dose of MS-222 (50 $\left.\mathrm{mg} \mathrm{L}^{-1}\right)$ failed to

217 induce I3 within the 3-min exposure period. The recovery time at higher concentrations (75 and 100

$218 \mathrm{mg} \mathrm{L}{ }^{-1}$ ) seemed to be similar, whereas the induction time at those concentrations was different.

219 Furthermore, the highest concentration of $125 \mathrm{mg} \mathrm{L}^{-1}$ resulted in 50\% mortality (Table 3); 75-100 mg

$220 \mathrm{~L}^{-1}$ of MS-222 led to no mortality during and after the treatment period of 7 days.

221 Table 3 Induction and recovery times for Pampus argenteus anaesthetized with six doses of MS-222

\begin{tabular}{|c|c|c|c|c|}
\hline \multirow{2}{*}{$\begin{array}{l}\text { Concentration } \\
\qquad\left(\mathrm{mg} \mathrm{L}^{-1}\right)\end{array}$} & \multicolumn{2}{|c|}{ Induction (s) } & \multirow{2}{*}{$\frac{\text { Recovery (s) }}{\text { R4 }}$} & \multirow[t]{2}{*}{ Recovery rate $(\%)$} \\
\hline & I1 & $\mathrm{I} 3$ & & \\
\hline 10 & $2147.3 \pm 20.3$ & - & - & 100 \\
\hline 25 & $2400.3 \pm 15.9$ & - & - & 100 \\
\hline 50 & $1092.3 \pm 18.5^{\mathrm{a}}$ & $2275.3 \pm 103.2^{\mathrm{a}}$ & $12.3 \pm 0.8^{\mathrm{a}}$ & 100 \\
\hline 75 & $41.33 \pm 4^{\mathrm{b}}$ & $167.5 \pm 50.7^{\mathrm{b}}$ & $35.5 \pm 3.8^{\mathrm{b}}$ & 100 \\
\hline 100 & $17.8 \pm 3.4^{\mathrm{c}}$ & $51.7 \pm 11.9^{\mathrm{c}}$ & $41.2 \pm 6.0^{\mathrm{b}}$ & 100 \\
\hline 125 & $7.0 \pm 0.9^{c}$ & $19.2 \pm 2.6^{\mathrm{c}}$ & $53.3 \pm 4.9^{c}$ & 50 \\
\hline \multicolumn{5}{|c|}{ Data are presented as mean \pm SD $(n=9)$. Statistical relationships between groups are indicated by } \\
\hline \multicolumn{5}{|c|}{ letters where significant differences were detected $(\mathrm{P}<0.05)$} \\
\hline
\end{tabular}




\section{Longest safe deep anesthesia time under the influence of LED}

223 The high anesthetic doses significantly reduced the time for $P$. argenteus to reach deep anesthesia.

224 However, excessive or persistent contact with the drug can eventually lead to death. Longer the fish 225 were exposed to MS-222, longer the recovery time needed (Table 4). After 12 and 15 min of deep 226 anesthesia, the LED of MS-222 resulted in 78\% and 33\% recovery rate, respectively; therefore, $10 \mathrm{~min}$

227 was the longest safe deep anesthesia time. At the end of each exposure (4, 7, or $10 \mathrm{~min})$, the fish reared

228 in the recovery tanks quickly showed normal behavior. No mortality was observed during and after the 229 treatment period of 7 days.

230 Table 4 Effect of LED on Pampus argenteus anesthetized with different deep anesthetic times

\begin{tabular}{|c|c|c|c|}
\hline $\begin{array}{c}\text { MS-222 } \\
\text { concentration } \\
\left(\mathrm{mg} \mathrm{L}^{-1}\right)\end{array}$ & $\begin{array}{l}\text { After fully anesthetized } \\
\text { continue anesthesia time (min) }\end{array}$ & $\begin{array}{l}\text { The average time required } \\
\text { for full recovery (s) }\end{array}$ & $\begin{array}{c}\text { Recovery rate } \\
(\%)\end{array}$ \\
\hline \multirow{5}{*}{75} & 4 & $43.3 \pm 6.7^{\mathrm{a}}$ & 100 \\
\hline & 7 & $62.5 \pm 4.5^{\mathrm{b}}$ & 100 \\
\hline & 10 & $182.0 \pm 4.9^{\mathrm{c}}$ & 100 \\
\hline & 12 & $212.7 \pm 11.8^{d}$ & 78 \\
\hline & 15 & $249.2 \pm 15.1^{\mathrm{e}}$ & 33 \\
\hline \multicolumn{4}{|c|}{ Data are presented as mean $\pm S D(n=9)$. Statistical relationships between groups are indicated by } \\
\hline
\end{tabular}

\section{$231 \quad$ Plasma cortisol}

232 Significant differences $(\mathrm{P}<0.05)$ in plasma cortisol levels were observed among the groups (Fig. 1).

233 The plasma cortisol levels of the DG, AG, and NAG groups significantly increased $(\mathrm{P}<0.05)$ by

234 1.3-fold, 1.1-fold, and 1.7-fold, respectively, when compared with the CG group $(22.620 \pm 0.836 \mathrm{ng}$

$\left.235 \mathrm{~mL}^{-1}\right)$. The plasma cortisol level of the NAG group was significantly different $(\mathrm{P}<0.05)$ from that of

236 the AG group, which exhibited the highest concentration $\left(38.739 \pm 1.065 \mathrm{ng} \mathrm{mL}^{-1}\right)$. 


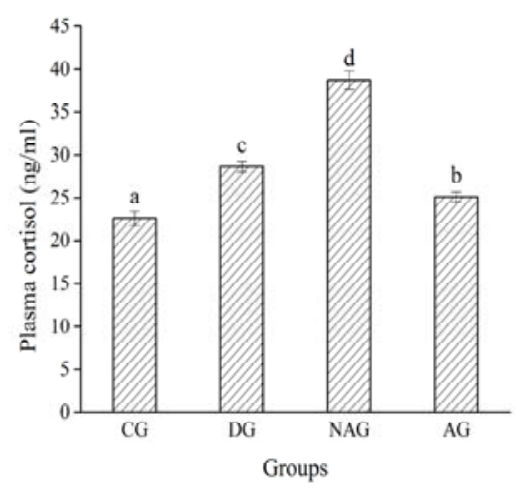

238 Figure 1. Effect of aquaculture treatment stresses on cortisol levels in plasma of juvenile silver pomfret.

239 Data represent mean \pm SD $(n=9)$. Statistical relationships between groups are indicated by letters

240 where significant differences were detected $(\mathrm{P}<0.05)$.

\section{Oxidative stress status in the liver}

242 The liver antioxidant capability of P. argenteus has been presented in Figure 2. When SOD, GSH,

243 MDA, and CAT activities of the NAG group were compared with those of the other three groups, a

244 significant increase $(\mathrm{P}<0.05)$ was observed. However, the DG and AG groups showed no significant

245 increase $(\mathrm{P}>0.05)$ in SOD, MDA, GSH, and CAT activities. In addition, GSH values of the DG and

246 AG groups were similar to the control values, and the CG and DG groups showed no significant

247 increase $(\mathrm{P}>0.05)$ in CAT activity. The AG group showed significantly $(\mathrm{P}<0.05)$ higher GSH, SOD,

248 CAT and MDA activities than the control before stress. 

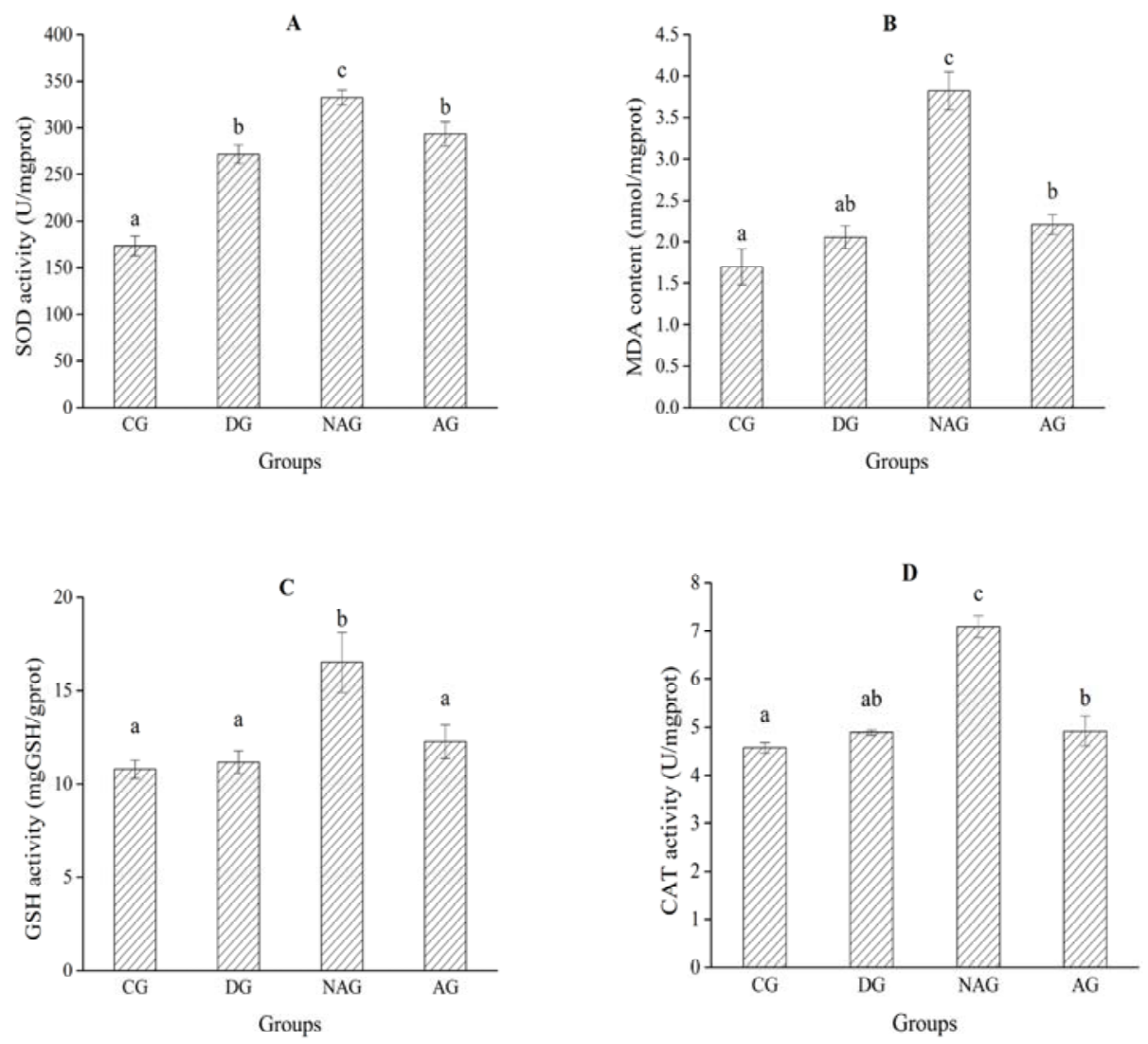

251 Figure 2. Effect of aquaculture treatment stresses on oxidative status [SOD (A), MDA (B), GSH (C),

252 CAT (D)] in liver of juvenile silver pomfret. Data represent mean $\pm \operatorname{SD}(n=9)$. Statistical relationships

253 between groups are indicated by letters where significant differences were detected $(\mathrm{P}<0.05)$.

\section{Stress-related gene expression in the kidney}

255 The mRNA expression levels of HSPs (HSP70 and HSP90) and GRs (GR1 and GR2) were 256 determined for P. argenteus (Fig. 3). Before aquaculture treatment, HSP70, HSP90, GR1, and GR2

257 mRNA levels showed no significant differences ( $>$ > 0.05), whereas HSP70, HSP90, GR1, and GR2

258 mRNA levels in the NAG group increased sharply. HSP70 and HSP90 mRNA levels in the AG group 259 showed no significant differences from the CG group $(\mathrm{P}>0.05)$, whereas the opposite was true for GR1 and GR2 mRNA levels. 


\section{1}

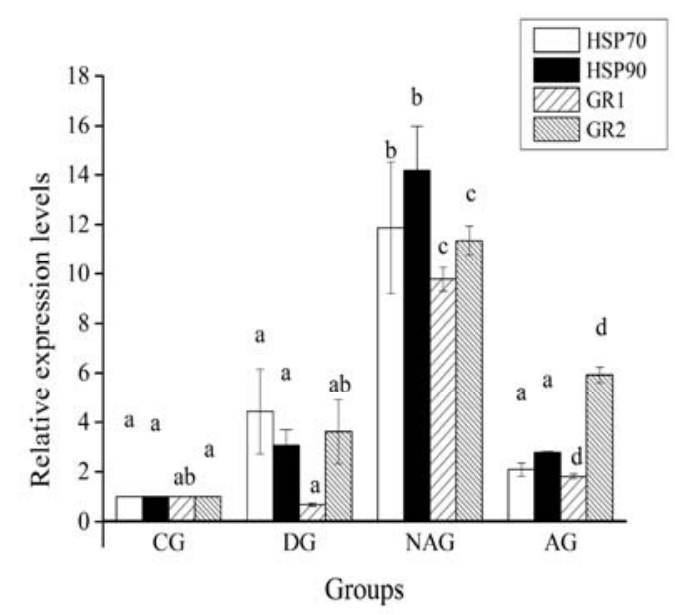

262 Figure 3. Expression levels of HSP70, HSP90, and GR1, GR2 mRNA in kidney of P. argenteus. The

263 expressions of target gene were normalized by $\beta$-actin expressions. Data represent mean \pm SD $(n=9)$.

264 Statistical relationships between groups are indicated by letters where significant differences were 265 detected $(\mathrm{P}<0.05)$.

\section{Discussion}

267 Although anesthetic agents are routinely used in aquaculture to reduce stress and physical injuries 268 during husbandry practices, their administration and efficacy in $P$. argenteus husbandry have received 269 scant attention. P. argenteus shows a strong response to stress, which can lead to death or accumulation 270 of mechanical damage; therefore, it is important to use methods that relieve the stress of $P$. argenteus.

271 MS-222 is particularly effective in fish because it is highly water- and lipid-soluble and readily crosses 272 the gill membrane (Vera et al., 2010). Although MS-222 is expensive, its beneficial effects ensure its 273 continuous application in research, food production, and ornamental fish rearing (Popovic et al., 2012).

274 Because species may differ widely in their response to an anesthetic, it is necessary to establish 275 appropriate concentrations of different anesthetic agents for each cultured species (Ross and Ross, 276 1999; Chambel et al., 2015). Factors such as body composition, sexual maturity, and gill surface to 277 body weight ratio, which may vary with species, size, and age, may be responsible for the variations in 278 the response (Zahl et al., 2011).

\section{LED and longest safe deep anesthetic time}


280 The results demonstrate that MS-222 is an effective and safe anesthetic for P. argenteus. Moreover,

281 our study defines the LED that produces desirable anesthetic effects in P. argenteus, namely, $75 \mathrm{mg} \mathrm{L}{ }^{-1}$.

282 An induction time of $3 \mathrm{~min}$ or less with complete recovery in $5 \mathrm{~min}$ is considered acceptable for fish

283 handling (Mohammadi and Khara, 2015). This dose produced induction and recovery times of less than

2843 and $5 \mathrm{~min}$, respectively. In general, the induction times decreased significantly as the doses increased

285 (Table 3). In contrast, the recovery times increased with increasing doses of MS-222 (Table 3). These

286 results are consistent with those reported in zebrafish for MS-222 (Grush et al., 2004), whereas the

287 recovery time for MS-222 was dose-independent in Senegalese sole (Weber et al., 2009). The

288 explanation for these variations can be related to the fact that increasing doses are also associated with

289 less time of contact of the fish with the anesthetic in the water, with a probable lower uptake of

290 MS-222. Thus, when the fish is placed in recovery, the anesthetic is rapidly cleared from the

291 bloodstream, which allows for a faster recovery (Weber et al., 2009). However, the molecular

292 characteristics of the anesthetic, as well as the physiological and metabolic characteristics of different

293 species, may influence the recovery time after anesthesia (Weber et al., 2011). With the prolongation of

294 the longest safe deep anesthesia time, the fish becomes more prone to death. In the present study, we

295 obtained a preliminary longest safe deep anesthesia time under LED. We can perform manual

296 operations during this period to reduce the stress on the fish body.

\section{Plasma cortisol}

298 Aquaculture inherently involves stressing the fish. Handling, transportation, and crowding are 299 common stressors in fish culture, which may affect their growth, feed intake, nutrient utilization, and 300 physiology. Plasma cortisol plays a central role in glucose metabolism during the physiological stress 301 response, and it can be used as an indicator of the acute stress response (Wendelaar Bonga, 1997).

302 The AG group displayed lower cortisol levels than the NAG and DG groups, which, to some extent, 303 corroborated with the efficacy of MS-222 in mitigating the stress of aquaculture. This result was 304 consistent with those of other studies, such as the results obtained after 10 min of enforced exercise in 305 Scophthalmus maximus (Van Ham et al., 2003), 5 min of confinement in Rutilus rutilus (Pottinger et al., 306 1999), and handling or confinement stress in Salmo trutta (Sumpter et al., 1985) at different 307 temperatures. In contrast, Davis et al. (1984) observed increased plasma corticosteroid levels when the 
308 fish were stressed by confinement. These disparities are dependent upon and possibly exacerbated by

309 the species, size, and life experience of the fish as well as the dosage of the anesthetic and type,

310 magnitude, and duration of the stressor (Weber et al., 2011).

311 In this study, the fish subjected to acute physical stress showed significantly elevated plasma

312 cortisol levels (levels in the NAG group were 1.7-fold those in the CG group). The maximum levels of

313 plasma cortisol in $P$. argenteus were somewhat lower than those in other fishes, such as the Arctic

314 charr (Backström et al., 2017) and Oncorhynchus kisutch (Talbot et al., 2009). Therefore, low but

315 significant levels of cortisol after stress could suggest that $P$. argenteus is sensitive to aquaculture

316 treatment stresses and stresses with significant effects on this species. Our results indicate that MS-222

317 effectively suppresses the cortisol stress response and may prove to be a useful anesthetic for reducing

318 the adverse effects of stress.

319 Antioxidant capability

320 Stressed fish have been demonstrated to be more vulnerable to disease because of impairment of the 321 antioxidant defense systems (Velisek et al., 2011). To cope with oxidative damage, organisms have 322 evolved a system to either prevent or repair the effects of oxidative stress (Birnie-Gauvin et al., 2017).

323 Oxidative stress is caused by the formation of reactive oxygen species ( $\mathrm{ROS}$ ), $\mathrm{H}_{2} \mathrm{O}_{2}$, hydroxyl radicals,

324 and superoxide anion radicals, which are the main by-products of oxidative metabolism and potentially

325 cause cell damage (Azzi et al., 2004).

326 In the present study, the SOD and CAT activities significantly increased $(\mathrm{P}<0.05)$ in the NAG

327 group. This indicates that aquaculture treatment stresses may cause oxidative stress in P. argenteus 328 juveniles because SOD and CAT represent the first line of defense against oxidative stress (Farombi et 329 al., 2007). To maintain a balance between antioxidants and ROS, SOD initially converts $\mathrm{O}^{2-}$ into $\mathrm{O}_{2}$ 330 and $\mathrm{H}_{2} \mathrm{O}_{2}$, and $\mathrm{H}_{2} \mathrm{O}_{2}$ is then broken down into $\mathrm{O}_{2}$ and $\mathrm{H}_{2} \mathrm{O}$ by CAT (Li et al., 2009b). CAT is mainly 331 located in the peroxisomes, and it is responsible for the reduction of $\mathrm{H}_{2} \mathrm{O}_{2}$ produced by the metabolism 332 of long-chain fatty acids in peroxisomes (Velisek et al., 2011). The SOD and CAT activities 333 significantly decreased $(\mathrm{P}<0.05)$ in the AG group when compared with the NAG group, but 334 significantly increased $(\mathrm{P}<0.05)$ when compared with the CG group. This indicates that MS-222 has a 335 calming effect, but its role is limited. It should be mentioned here that MS-222 significantly reduced 
336 MDA content in the liver, indicating that MS-222 could inhibit lipid peroxidation. This was supported

337 by the fact that MDA is a commonly used indicator to evaluate the toxic processes caused by free

338 radicals (Parvez and Raisuddin, 2005). In addition, the NAG group showed significantly increased $(\mathrm{P}<$

339 0.05) GSH levels when compared with the AG group, but no significant changes were observed when

340 compared with the DG group. Glutathione reductase plays an important role in cellular antioxidant

341 protection and adjustment processes of the metabolic pathways (Wendelaar Bonga, 1997). Glutathione

342 reductase catalyzes the reduction of glutathione disulfide to reduced GSH in an NADPH-dependent

343 reaction (Cazenave et al., 2006). The CAT and GSH activities and MDA contents of the DG group

344 were similar to those of the CG group; however, the SOD activities were significantly increased $(\mathrm{P}<$

345 0.05) in the DG group. This is probably because drainage is slow and has little influence on oxidative

346 stress. Consistent with those results, In the present study, fish in the NAG group showed more

347 oxidative damage than the control group, which is consistent with this finding; therefore, MS-222 has

348 some functions against this type of damage. This suggests that MS-222 $\left(75 \mathrm{mg} \mathrm{L}^{-1}\right)$ can contribute to

349 the health of $P$. argenteus during aquaculture treatments.

350 Stress-related gene expression

351 HSPs, which represent a subset of molecular chaperones, are part of the cellular defense. Within the 352 HSP family, HSP70 and HSP90 play a key role in maintaining cellular homeostasis and protecting the 353 organism after stress(Fu et al., 2011; Liu et al., 2013). Previous studies have shown that HSPs can be 354 regulated by environmental stresses such as heat shock, bacterial challenge, and heavy metals (Farcy et 355 al., 2007) (Ivanina et al., 2009). We observed that the mRNA levels of HSP70 and HSP90 were 356 significantly higher $(\mathrm{P}<0.05)$ in the NAG group than in the other three groups. In addition, no obvious 357 differences in HSP70 and HSP90 mRNA expression levels were observed between the AG and CD 358 groups. When the fish were exposed to stress, over-expression of HSP70 and HSP90 may have been 359 immediately induced to help the cells relieve stress and adapt to the external environmental changes 360 (Ceyhun et al., 2010). This result was consistent with those of the ammonia toxicity test on Takifugu 361 obscurus (Cheng et al., 2015) and Botia reevesae (Qin et al., 2013). To understand the functions of 362 HSPs, the gene sequences of many marine organisms have been cloned and detected, including the 363 rainbow trout (Ojima et al., 2005), Chinese mitten crab (Li et al., 2009a), black tiger shrimp 
364 (Rungrassamee et al., 2010), and silver sea bream (Deane and Woo, 2005). Previous studies have

365 suggested that HSP70 is induced under a certain range of stress, which is a protective mechanism to 366 counteract the effect of stress on cultured animals (Iwama et al., 1998). However, HSP70 in the 367 rainbow trout and tilapia was significantly inhibited under different high-temperature stresses (Basu et 368 al., 2001). A previous study on the Atlantic salmon showed that low temperature, capture, and other 369 stress factors did not significantly influence the HSP levels in the body (Zarate and Bradley, 2003). The 370 reasons for this inconsistency may be related to the type of stress protein. Overall, the mechanisms by 371 which HSPs protect cells under stressful conditions are complex and need to be studied further.

372 In the AG group, HSP70 and HSP90 mRNA levels were unaffected by stress, whereas GR1 and 373 GR2 mRNA levels were significantly higher $(\mathrm{P}<0.05)$ after stress. This may be because GRs are more 374 sensitive to stress, even after MS-222 administration. In teleosts, two types of GRs (GR1 and GR2) are 375 present, and their functions are affected by the environment and species. For instance, in the Indian 376 ricefish, Oryzias dancena, GR1 is believed to be activated only under stressful conditions, and GR2 is 377 activated under non- or mildly stressful conditions (Kim et al., 2011). Sun et al. (Sun et al., 2017) 378 suggested that GR1 is expressed only under stress in P. argenteus. In this study, the expression levels 379 of GR1 and GR2 were significantly different between the control and aquaculture treatment groups. 380 Further studies are required to understand the functional model of GRs in this species. In this study, the 381 upregulated mRNA expression levels of HSP70, HSP90, GR1, and GR2 after aquaculture treatment 382 stresses indicate that the HSPs are inducible and may play an important role in the immune response.

383 The mRNA expression levels of HSP70, HSP90, GR1, and GR2 did not differ between the CG and DG

384 groups, indicating that drainage during aquaculture has negligible effects on the expression of 385 stress-related genes.

386 In summary, MS-222 can be used as an anesthetic for P. argenteus juveniles. The most suitable 387 concentration of MS-222 for attaining deep anesthesia was $75 \mathrm{mg} \mathrm{L}^{-1}$. An appropriate concentration of 388 MS-222 for sedation can reduce fish activity, facilitate handling procedures, and allow rapid recovery, 389 thereby enhancing the safety of the aquaculture treatment. Aquaculture treatment stresses can cause 390 great damage to P. argenteus, and MS-222 (75 $\left.\mathrm{mg} \mathrm{L}^{-1}\right)$ can help this species to resist the stresses.

\section{Acknowledgments}



iency.

Alsop, D. and Vijayan, M. M. (2008). Development of the corticosteroid stress axis and receptor expression in zebrafish. Am J Physiol Regul Integr Comp Physiol. 294, R711-R719.

Azad, I. S., Al-Marzouk, A., James, C. M., Almatar, S. and Al-Gharabally, H. (2007). Scuticociliatosis-associated mortalities and histopathology of natural infection in cultured silver pomfret (Pampus argenteus Euphrasen) in Kuwait. Aquaculture. 262, 202-210.

Azzi, A., Davies, K. J. and Kelly, F. (2004). Free radical biology-terminology and critical thinking. Febs Lett. 558, 3-6.

Backström, T., Heynen, M., Brännäs, E., Nilsson, J., Winberg, S. and Magnhagen, C. (2017). Anaesthesia and handling stress effects on pigmentation and monoamines in Arctic charr. Environ. Biol. Fishes. 100, 1-10.

Bamberger, C. M., Schulte, H. M. and Chrousos, G. P. (1996). Molecular determinants of glucocorticoid receptor function and tissue sensitivity to glucocorticoids. Endocrine Reviews. 17, 245-61.

Barata, M., Soares, F., Aragão, C., Almeida, A. C., Pousão-Ferreira, P. and Ribeiro, L. (2016). Efficiency of 2-phenoxyethanol and Clove Oil for Reducing Handling Stress in Reared Meagre, Argyrosomus regius (Pisces: Sciaenidae). J. World Aquacult. Soc. 47, 82-92.

Basu, N., Nakano, T., Grau, E. G. and Iwama, G. K. (2001). The effects of cortisol on heat shock protein 70 levels in two fish species. Gen Comp Endocrinol. 124, 97-105.

Bern, H. A. (1967). Hormones and endocrine glands of fishes. Studies of fish endocrinology reveal major physiologic and evolutionary problems. Science. 158, 455-462.

Birnie-Gauvin, K., Costantini, D., Cooke, S. J. and Willmore, W. G. (2017). A comparative and evolutionary approach to oxidative stress in fish: A review. Fish. Fish. 18, 928-942.

Bury, N. R., Sturm, A., Le, R. P., Lethimonier, C., Ducouret, B., Guiguen, Y., Robinson-Rechavi, M., Laudet, V., Rafestin-Oblin, M. E. and Prunet, P. (2003). Evidence for two distinct functional glucocorticoid receptors in teleost fish. J. Mol. Endocrinol. 31, 141-156. detoxification and antioxidant response in diverse organs of Corydoras paleatus experimentally exposed to microcystin-RR. Aquat. Toxicol. 76, 1-12. 
Ceyhun, S. B., Şentürk, M., Ekinci, D., Erdoğan, O., Çiltaş, A. and Kocaman, E. M. (2010). Deltamethrin attenuates antioxidant defense system and induces the expression of heat shock protein 70 in rainbow trout. Comp. Biochem. Physiol. C-Toxicol. 152, 215-223.

Chambel, J., Pinho, R., Sousa, R., Ferreira, T., Baptista, T., Severiano, V., Mendes, S. and Pedrosa, R. (2015). The efficacy of MS-222 as anaesthetic agent in four freshwater aquarium fish species. Aquac. Res. 46, 1582-1589.

Charmandari, E., Tsigos, C. and Chrousos, G. (2005). Endocrinology of the stress response. Annu. Rev. Physiol. 67, 259-284.

Cheng, C. H., Yang, F. F., Ling, R. Z., Liao, S. A., Miao, Y. T., Ye, C. X. and Wang, A. L. (2015). Effects of ammonia exposure on apoptosis, oxidative stress and immune response in pufferfish (Takifugu obscurus). Aquat. Toxicol. 164, 61-71.

Davis, K., MaryAnnaSuttle and Parker, N. (1984). Biotic and Abiotic Influences on Corticosteroid Hormone Rhythms in Channel Catfish. Trans. Am. Fish. Soc. 113, 414-421.

Deane, E. E. and Woo, N. Y. (2005). Cloning and characterization of the hsp70 multigene family from silver sea bream: Modulated gene expression between warm and cold temperature acclimation. Biochem. Biophys. Res. Commun. 330, 776-83.

Ducouret, B., Tujague, M., Ashraf, J., Mouchel, N., Servel, N., Valotaire, Y. and Thompson, E. B. (1995). Cloning of a teleost fish glucocorticoid receptor shows that it contains a deoxyribonucleic acid-binding domain different from that of mammals. Endocrinology. 136, 3774-3783.

Farcy, E., Serpentini, A., Fiévet, B. and Lebel, J. M. (2007). Identification of cDNAs encoding HSP70 and HSP90 in the abalone Haliotis tuberculata: Transcriptional induction in response to thermal stress in hemocyte primary culture. Comp. Biochem. Physiol. B-Biochem. Mol. Biol. 146, 540-550.

Farombi, E. O., Adelowo, O. A. and Ajimoko, Y. R. (2007). Biomarkers of Oxidative Stress and Heavy Metal Levels as Indicators of Environmental Pollution in African Cat Fish (Clarias gariepinus) from Nigeria Ogun River. Int J Environ Res Public Health 4, 158-165.

Fu, D., Chen, J., Zhang, Y. and Yu, Z. (2011). Cloning and expression of a heat shock protein (HSP) 90 gene in the haemocytes of Crassostrea hongkongensis under osmotic stress and bacterial challenge. Fish Shellfish Immunol. 31, 118-125.

Grush, J., Noakes, D. L. and Moccia, R. D. (2004). The efficacy of clove oil as an anesthetic for the zebrafish, Danio rerio (Hamilton). Zebrafish. 1, 46-53.

Heo, G. J. and Shin, G. (2010). Efficacy of benzocaine as an anaesthetic for Crucian carp (Carassius carassius). Vet. Anaesth. Analg. 37, 132-135.

Huang, X., Yin, Y., Shi, Z., Li, W., Zhou, H. and Lv, W. (2010). Lipid content and fatty acid composition in wild-caught silver pomfret (Pampus argenteus) broodstocks: Effects on gonad development. Aquaculture. 310, 192-199.

Ivanina, A. V., Taylor, C. and Sokolova, I. M. (2009). Effects of elevated temperature and cadmium exposure on stress protein response in eastern oysters Crassostrea virginica (Gmelin). Aquat. Toxicol. 91, 245-254.

Iwama, G. K., Thomas, P. T., Forsyth, R. B. and Vijayan, M. M. (1998). Heat shock protein expression in fish. Rev. Fish. Biol. Fish. 8, 35-56. 
Jiang, J., Shi, Y., Shan, Z., Yang, L., Wang, X. and Shi, L. (2012). Bioaccumulation, oxidative stress and HSP70 expression in Cyprinus carpio L. exposed to microcystin-LR under laboratory conditions. Comp. Biochem. Physiol. C-Toxicol. Pharmacol. 155, 483-490.

Kim, M. A., Kim, D. S. and Sohn, Y. C. (2011). Characterization of two functional glucocorticoid receptors in the marine medaka Oryzias dancena. Gen Comp Endocrinol. 171, 341-349.

Li, P., Zha, J., Zhang, Z., Huang, H., Sun, H., Song, D. and Zhou, K. (2009a). Molecular cloning, mRNA expression, and characterization of HSP90 gene from Chinese mitten crab Eriocheir japonica sinensis. Comp. Biochem. Physiol. B-Biochem. Mol. Biol. 153, 229-235.

Li, S., Xu, J. and Sheng, L. (2014). The trans-generation effect during pulsed cadmium exposure: Tolerance and induction of hsp70. Ecotox. Environ. Safe. 107, 300-305.

Li, Z. H., Xie, S., Wang, J. X., Sales, J., Li, P. and Chen, D. Q. (2009b). Effect of intermittent starvation on growth and some antioxidant indexes of Macrobrachium nipponense (De Haan). Aquac. Res. 40, 526-532.

Liao, K., Meng, R., Ran, Z., Cheng, G., Wang, Y., Xu, J., Xu, S. and Yan, X. (2017). Short-term starvation in silver pomfret (Pampus argenteus): molecular effects on lipid mobilization and utilization. Aquac. Res. 48, 4874-4885.

Liu, B., Xu, L., Ge, X., Xie, J., Xu, P., Zhou, Q., Pan, L. and Zhang, Y. (2013). Effects of mannan oligosaccharide on the physiological responses, HSP70 gene expression and disease resistance of Allogynogenetic crucian carp (Carassius auratus gibelio) under Aeromonas hydrophila infection. Fish Shellfish Immunol. 34, 1395-1403.

Liu, W. and Zhan, B. (1999). Analysis on the Exploitation of Pampus spp. in the East China Sea. Journal of Zhanjiang Ocean University. 1, 30-34.

Ming, J., Xie, J., Xu, P., Liu, W., Ge, X., Liu, B., He, Y., Cheng, Y., Zhou, Q. and Pan, L. (2010). Molecular cloning and expression of two HSP70 genes in the Wuchang bream (Megalobrama amblycephala Yih). Fish Shellfish Immunol. 28, 407-418.

Mohammadi, M. and Khara, H. (2015). Effect of different anesthetic agents (clove oil, tricaine methanesulfonate, ketamine, tobacco) on hematological parameters and stress indicators of rainbow trout Oncorhynchus mykiss, Walbaum, 1792. Comparative Clinical Pathology. 24, 1039-1044.

Mommsen, T. P., Vijayan, M. M. and Moon, T. W. (1999). Cortisol in teleosts: dynamics, mechanisms of action, and metabolic regulation. Rev. Fish. Biol. Fish. 9, 211-268.

Ojima, N., Yamashita, M. and Watabe, S. (2005). Comparative expression analysis of two paralogous Hsp70s in rainbow trout cells exposed to heat stress. Biochimica Et Biophysica Acta. 1681, 99-106.

Parvez, S. and Raisuddin, S. (2005). Protein carbonyls: novel biomarkers of exposure to oxidative stress-inducing pesticides in freshwater fish Channa punctata (Bloch). Environ. Toxicol. Pharmacol. 20, 112-117.

Pierron, F., Bourret, V., Stcyr, J., Campbell, P. G. C., Bernatchez, L. and Couture, P. (2009). Transcriptional responses to environmental metal exposure in wild yellow perch (Perca flavescens) collected in lakes with differing environmental metal concentrations ( $\mathrm{Cd}, \mathrm{Cu}, \mathrm{Ni})$. Ecotoxicology. 18, 620-631. 
Popovic, N. T., Strunjak-Perovic, I., Coz-Rakovac, R., Barisic, J., Jadan, M., Berakovic, A. P. and Klobucar, R. S. (2012). Tricaine methane-sulfonate (MS-222) application in fish anaesthesia. $J$. Appl. Ichthyol. 28, 553-564.

Pottinger, T. G., Yeomans, W. E. and Carrick, T. R. (1999). Plasma cortisol and 17 $\beta$-oestradiol levels in roach exposed to acute and chronic stress. J. Fish Biol. 54, 525-532.

Qin, C., Zhao, D., Gong, Q., Qi, Z., Zou, Y., Yue, X. and Xie, B. (2013). Effects of pathogenic bacterial challenge after acute sublethal ammonia-N exposure on heat shock protein 70 expression in Botiareevesae. Fish Shellfish Immunol. 35, 1044-1047.

Ross, L. G. and Ross, B. (1999). Anaesthetic and sedative techniques for aquatic animals. J. Fish Biol. 56, 1562-1563.

Rungrassamee, W., Leelatanawit, R., Jiravanichpaisal, P., Klinbunga, S. and Karoonuthaisiri, N. (2010). Expression and distribution of three heat shock protein genes under heat shock stress and under exposure to Vibrio harveyi in Penaeus monodon. Dev. Comp. Immunol. 34, 1082-1089.

Schoneveld, O. J., Gaemers, I. C. and Lamers, W. H. (2004). Mechanisms of glucocorticoid signalling. Biochim Biophys Acta. 1680, 114-128.

Shi, Z. H., Zhao, F., Rong-Bing, F. U., Huang, X. X. and Wang, J. G. (2009a). Study on artificial larva rearing techniques of silver pomfret (Pampus argenteus). Marine Fisheries. 31, 53-57.

Shi, Z. H., Zhao, F., Wang, J. G., Shi-Ming, P. and Wang, H. P. (2009). Artificial insemination and incubation of silver pomfret (Pampus argenteus) from Zhoushan fishing ground. Fishery Modernization. 36, 18-21.

Stolte, E., De-Mazon, A. K., Km, Jesiak, M., Bury, N., Sturm, A., Savelkoul, H., Van-Kemenade, B. and Flik, G. (2008). Corticosteroid receptors involved in stress regulation in common carp, Cyprinus carpio. J. Endocrinol. 198, 403-17.

Sulaimanm, A. and Charlesm, J. (2007). Performance of Different Types of Commercial Feeds on the Growth of Juvenile Silver Pomfret, Pampus argenteus, under Tank Culture Conditions. J. World Aquacult. Soc. 38, 550-556.

Sumpter, J. P., Pickering, A. D. and Pottinger, T. G. (1985). Stress-induced elevation of plasma alpha-MSH and endorphin in brown trout, Salmo trutta L.Gen. Comp. Endocrinol. 59, 257-265.

Sun, P., Yin, F. and Tang, B. (2017). Effects of Acute Handling Stress on Expression of Growth-Related Genes in Pampus argenteus. J. World Aquacult. Soc. 48, 166-179.

Tagawa, M., Hagiwara, H., Takemura, A., Hirose, S. and Hirano, T. (1997). Partial cloning of the hormone-binding domain of the cortisol receptor in tilapia, Oreochromis mossambicus, and changes in the mRNA level during embryonic development. Gen. Comp. Endocrinol. 108, 132-140.

Talbot, A. T., Pottinger, T. G., Smith, T. J. and Cairns, M. T. (2009). Acute phase gene expression in rainbow trout (Oncorhynchus mykiss) after exposure to a confinement stressor: A comparison of pooled and individual data. Fish Shellfish Immunol. 27, 309-317.

Van Ham, E. H., Van Anholt, R. D., Kruitwagen, G., Imsland, A. K., Foss, A., Sveinsbø, B. O., Fitzgerald, R., Parpoura, A. C., Stefansson, S. O. and Bonga, S. E. (2003). Environment affects stress in exercised turbot. Comp. Biochem. Physiol. A-Mol. Integr. Physiol. 136, 525-538.

Velisek, J., Stara, A., Li, Z. H., Silovska, S. and Turek, J. (2011). Comparison of the effects of four anaesthetics on blood biochemical profiles and oxidative stress biomarkers in rainbow trout. Aquaculture. 310, 369-375. 
Vera, L. M., Rossánchez, G., Garcíamateos, G. and Sánchezvázquez, F. J. (2010). MS-222 toxicity in juvenile seabream correlates with diurnal activity, as measured by a novel video-tracking method. Aquaculture. 307, 29-34.

Wagner, G. N., Singer, T. D. and Scott Mckinley, R. (2015). The ability of clove oil and MS-222 to minimize handling stress in rainbow trout (Oncorhynchus mykiss Walbaum). Aquac. Res. 34, 1139-1146.

Wang, W., Vinocur, B., Shoseyov, O. and Altman, A. (2004). Role of plant heat-shock proteins and molecular chaperons in the abiotic stress response. Trends Plant Sci. 9, 244-252.

559 Weber, R. A., Pérezmaceira, J. J., Peleteiro, J. B., Garcíamartín, L. and Aldegunde, M. (2011). Effects of acute exposure to 2-phenoxyethanol, clove oil, MS-222, and metomidate on primary and secondary stress responses in Senegalese sole (Solea senegalensis Kaup 1858). Aquaculture. 321, 108-112.

Weber, R. A., Peleteiro, J. B., García Martín, L. O. and Aldegunde, M. (2009). The efficacy of 2-phenoxyethanol, metomidate, clove oil and MS-222 as anaesthetic agents in the Senegalese sole (Solea senegalensis Kaup 1858). Aquaculture. 288, 147-150.

Wendelaar Bonga, S. E. (1997). The stress response in fish. Physiol. Rev. 77, 591-625.

Zahl, I. H., Kiessling, A., Samuelsen, O. B. and Hansen, M. K. (2011). Anaesthesia of Atlantic halibut (Hippoglossus hippoglossus) Effect of pre-anaesthetic sedation, and importance of body weight and water temperature. Aquac. Res. 42, 1235-1245.

570 Zarate, J. and Bradley, T. M. (2003). Heat shock proteins are not sensitive indicators of hatchery stress in salmon. Aquaculture. 223, 175-187.

572 Zhang, C., Gao, Q., Peng, S., Shi, Z. and Wang, J. (2017). Substitution of Dietary Fish Oil with Soybean Oil Influences Stress Indexes and Tissue Antioxidant Function of Silver Pomfret( Pampus argenteus) before and after Transportation. Chinese Journal of Animal Nutrition. 29, 354-364. and HSP90 expressions of blunt snout bream (Megalobrama amblycephala) under high ammonia 


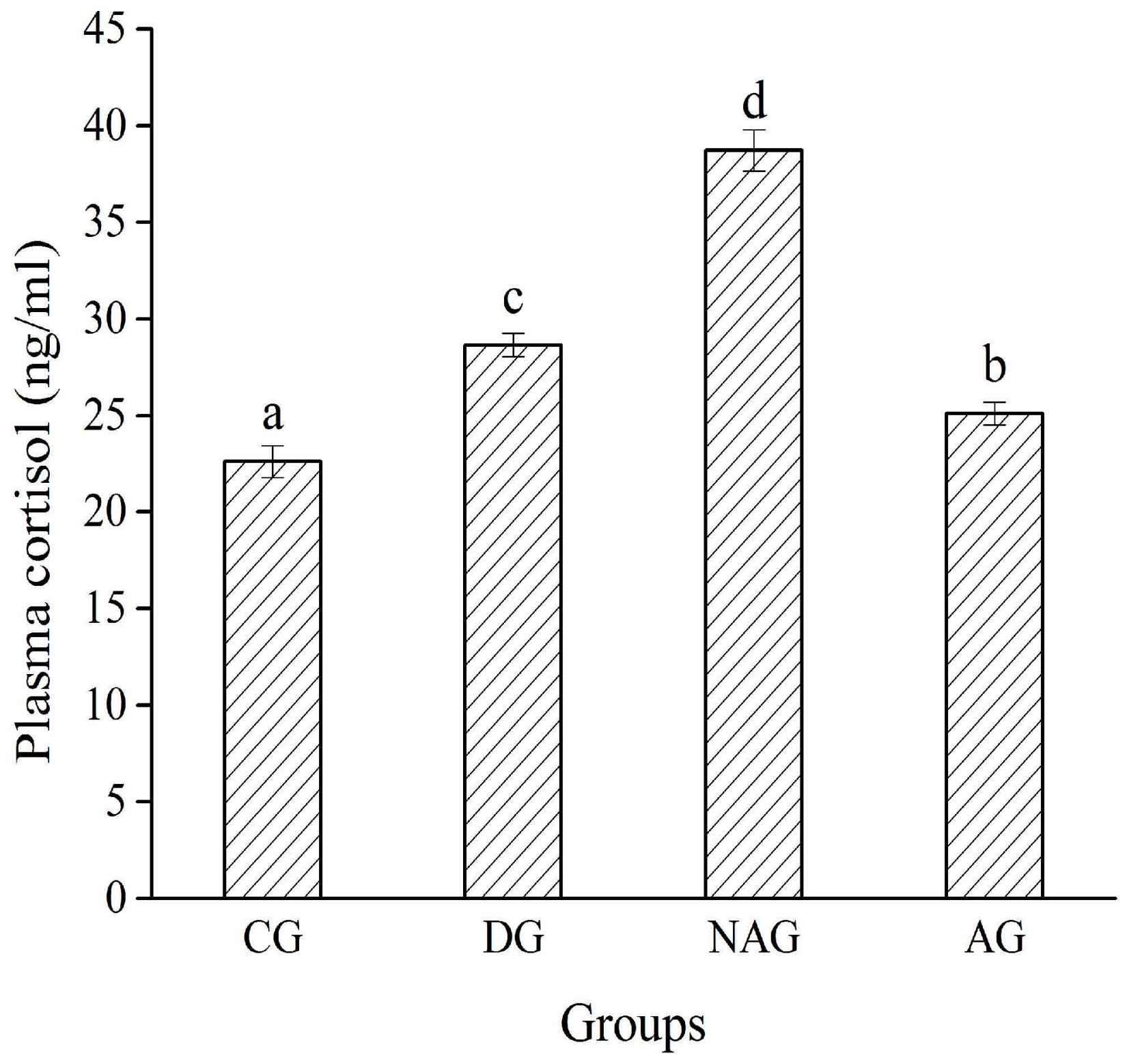




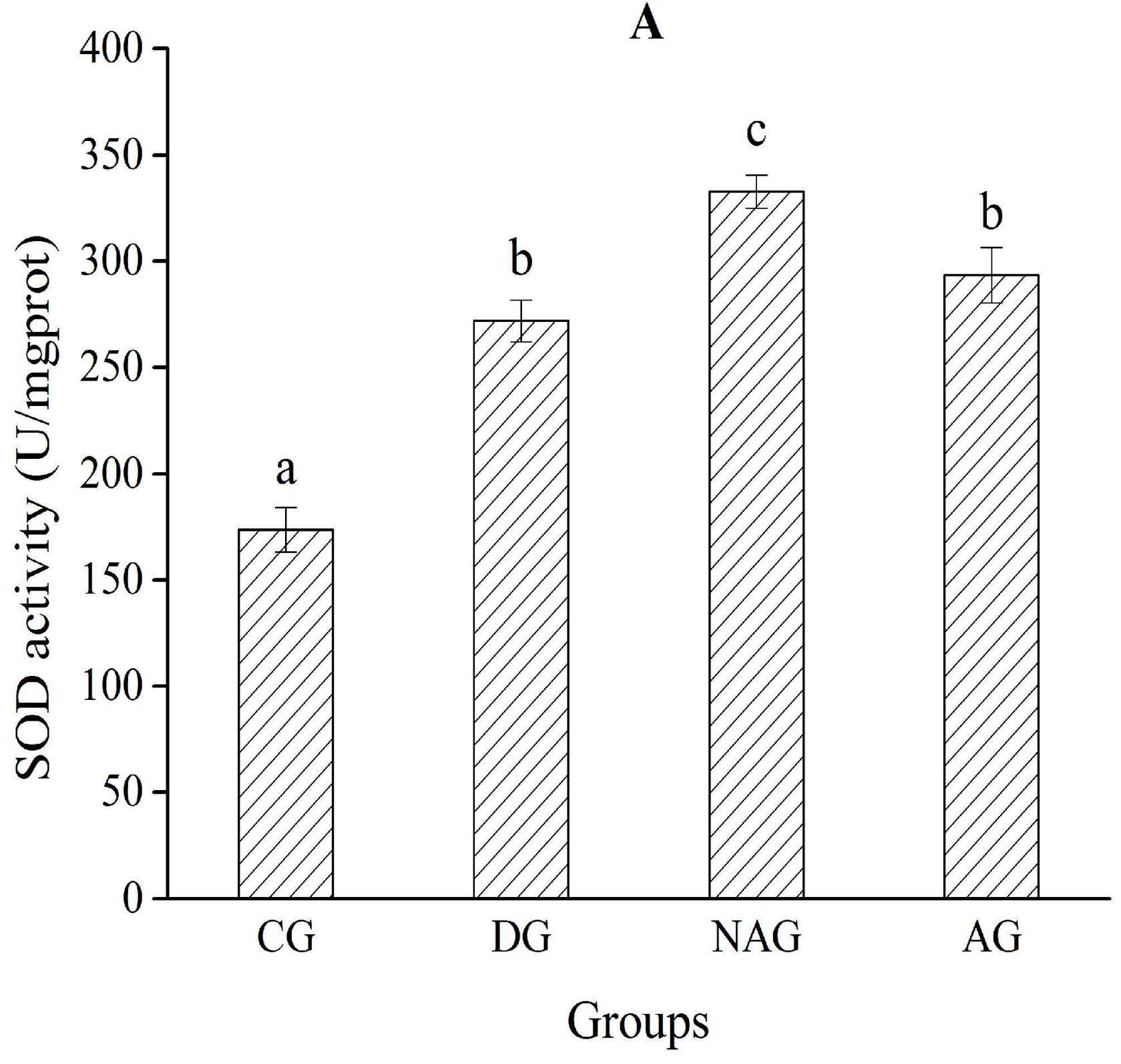




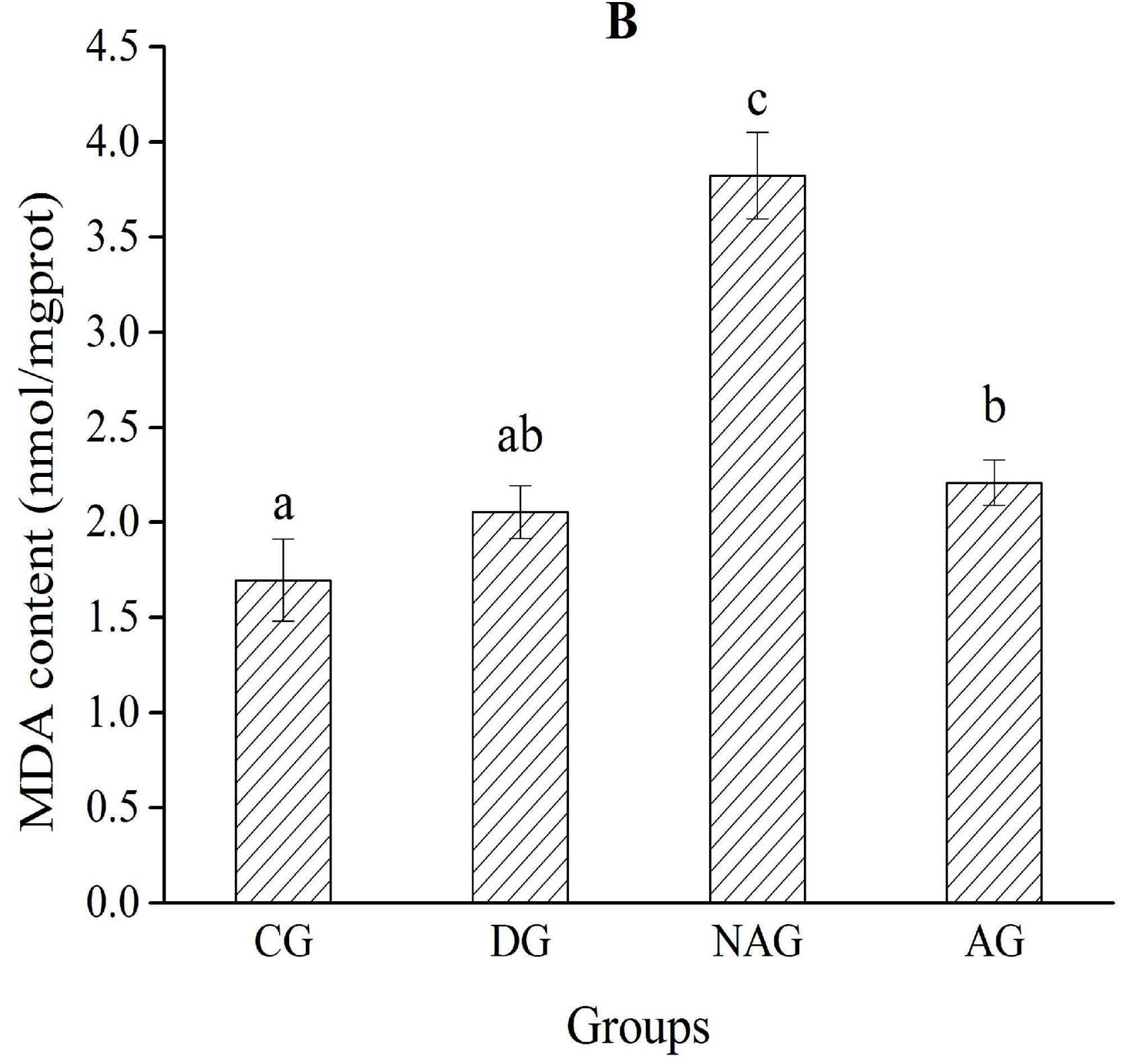




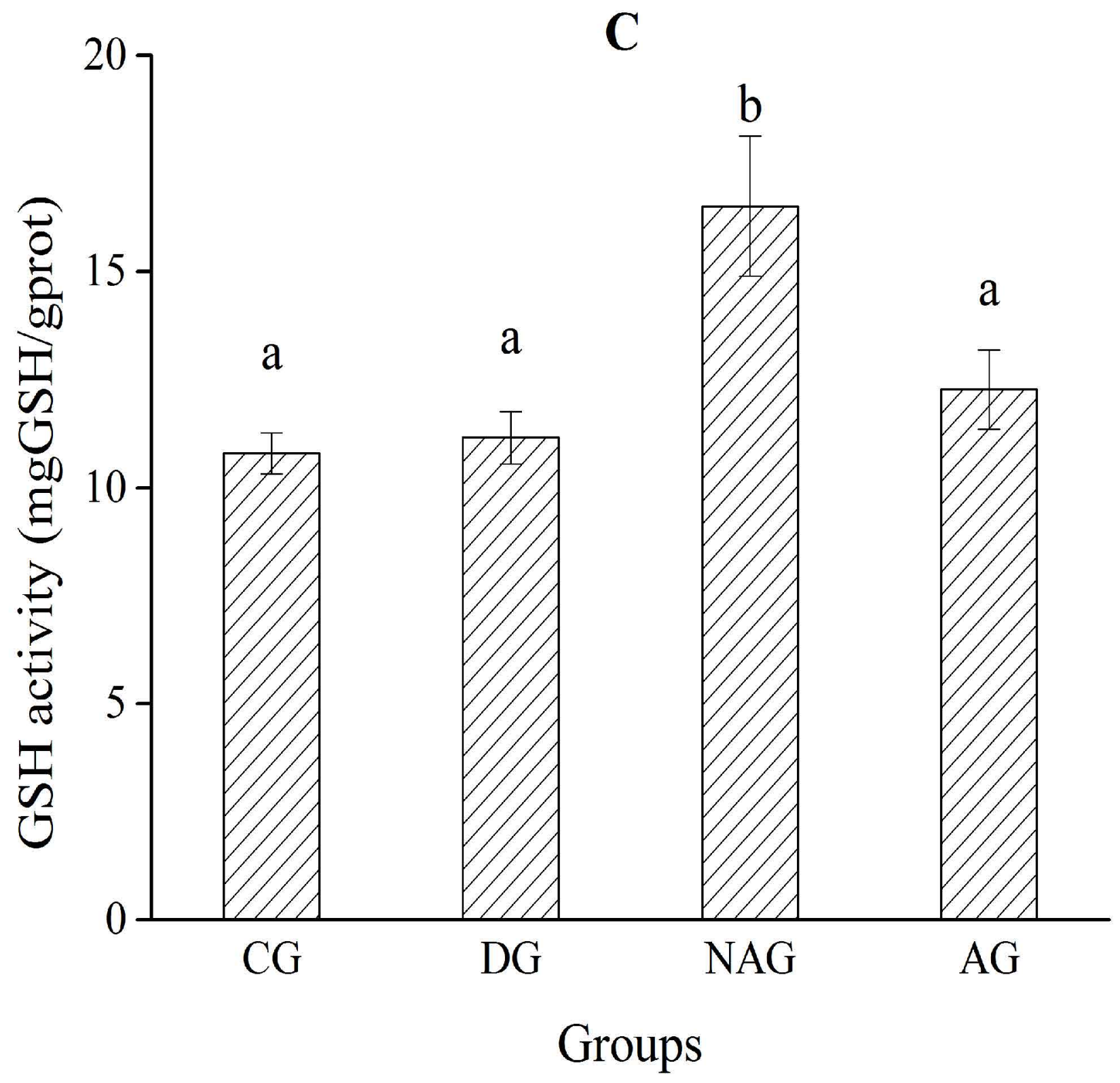




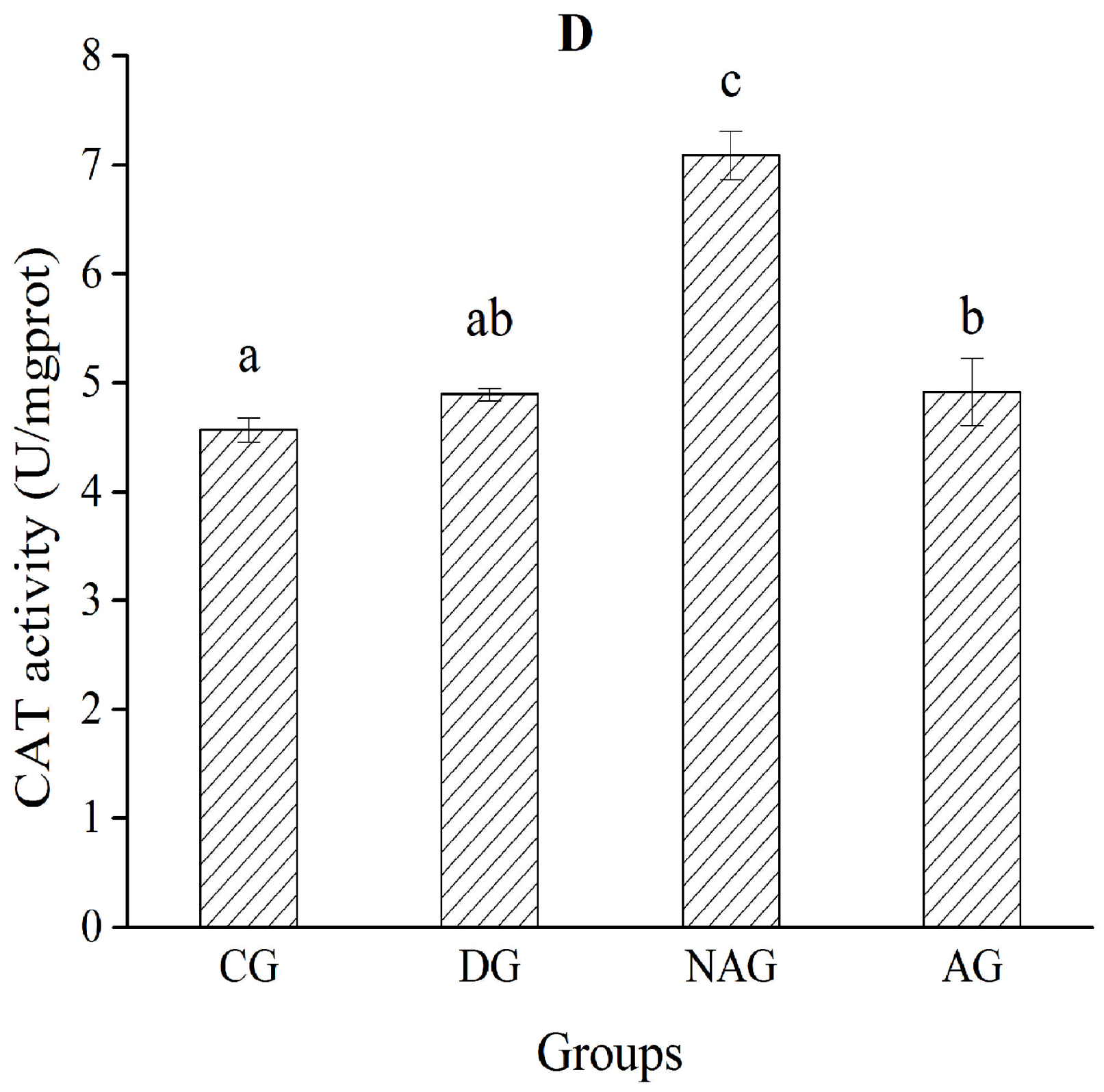




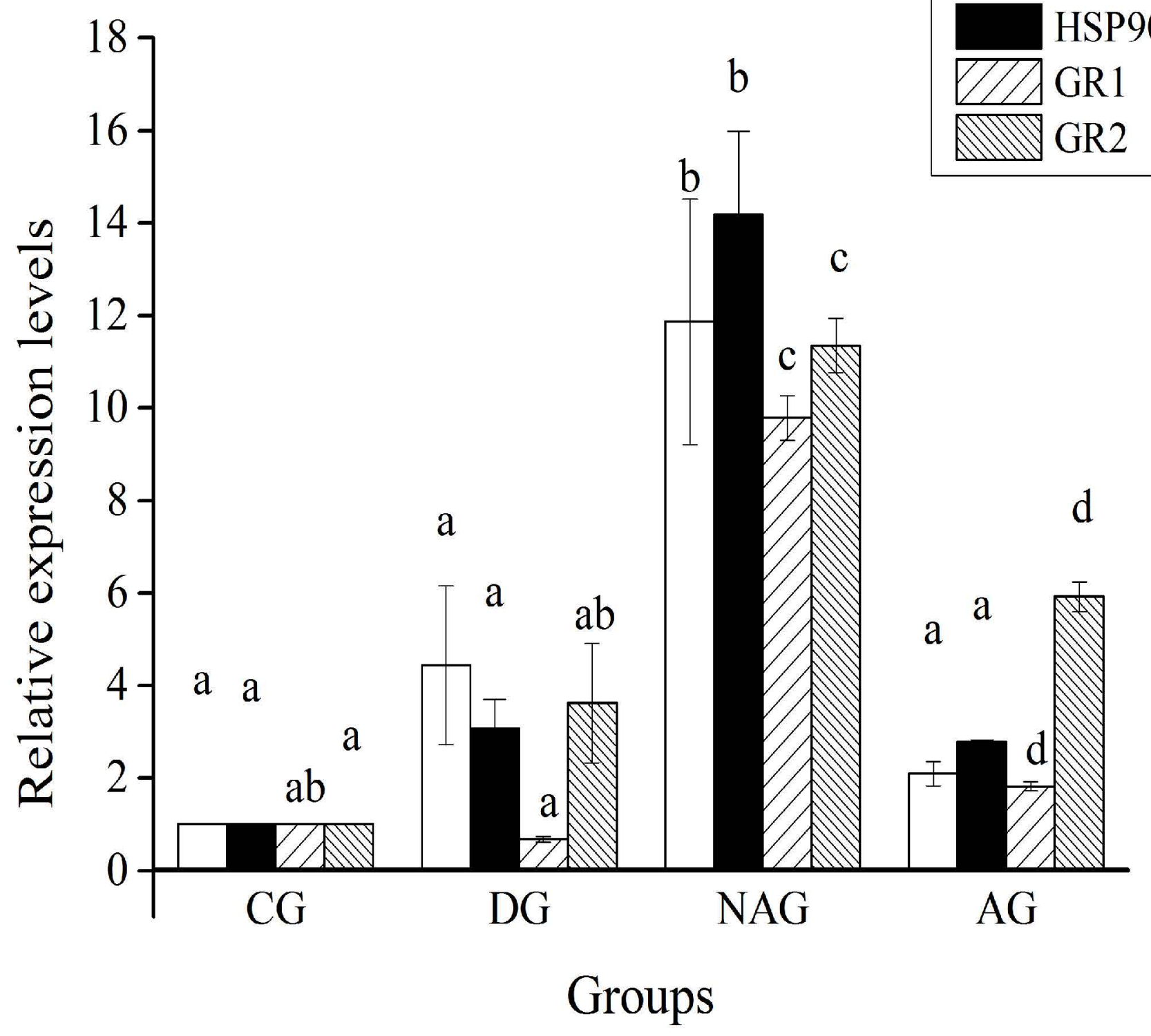

